Témoigner Témoigner. Entre histoire et mémoire

Getuigen Revue pluridisciplinaire de la Fondation Auschwitz

118 | 2014

Au nom des victimes. Dictature et terreur d'État en Argentine, Chili et Uruguay

\title{
Mémorandum théâtral
}

A theatrical memorandum

Een theatraal memorandum

Isabelle Galichon

URL : http://journals.openedition.org/temoigner/1241

DOI : 10.4000/temoigner.1241

ISSN : 2506-6390

Éditeur :

Éditions du Centre d'études et de documentation Mémoire d'Auschwitz, Éditions Kimé

Édition imprimée

Date de publication : 1 octobre 2014

Pagination : 33

ISBN : 978-2-84174-674-3

ISSN : 2031-4183

Référence électronique

Isabelle Galichon, « Mémorandum théâtral », Témoigner. Entre histoire et mémoire [En ligne], 118| 2014, mis en ligne le 01 octobre 2015, consulté le 23 octobre 2020. URL : http://journals.openedition.org/ temoigner/1241; DOI : https://doi.org/10.4000/temoigner.1241 


\section{DANSER LE RÉEL}

RENCONTRE Exercice du corps, au sens spirituel et chorégraphique, pour un récit sans parole sur la persécution des Tsiganes.

A près avoir assisté dans les arènes de la Maestranza de Séville à Arena (six chorégraphie sur la tauromachie), Georges Didi-Huber" une dialectique du montage » : « Il faut un acte qui réunisse la cruauté d'un découpage, c'est-à-dire d'une mise à mort, et la suavité d'une danse ou d'une mise en 2006, 178). (Le danseur des solitudes, Paris, Minuit 2006, p. 178). Dans son dernier ballet, Lo real/Le réel/ The real, Israel Galvan renoue avec cette tension dral'orique qui, toujours selon Didi-Huberman, serait rorigine de loeuvre dart, en questionnant la perséce saisit d'un ternination des Gitans par les nazis. I se saisit d'un temps qui n'est plus celui de la danse ni fin de cetétat de choses sa dernière œuvre sur lans $L a$ fin de cet état de choses, sa dernière œuvre sur l'Apocal'histoire Il rompt histoire. Il rompt alors avec cette forme de solitude qui caractérise ses chorégraphies et sculpte son corps vise l'́pure pour un danser en qu (ibid, p. 15). Ve thème quil puise dans une histoire qu'il n'a cese cententre depuis son enfance le mène sul na terse dérilleux de Sila dép de la mise en scène de la barbarie du nazisme. Sila déportation des Gitans demeure un sujet peu prélant parvientà dépserlec corcére lan, parvient à dépasser le caractère problénatique de a spenta du peuple gitan, pouvait alors exprimer cette réalité du peuple gitan, pouvait alors exprimer cette réalite

Le premier tableau, « Préface : on tranche l’air », place d'emblée le spectateur dans la geste flamenca que revisite Galvan. Mais ici, nul temple $e^{1}$, nulle domesticade dilatation du mouvement: le bras sallonge et fert lespace jus du mouvement. le bras sallonge et fend lutions pour une linéarité parfaite. L'air, l'espace, le

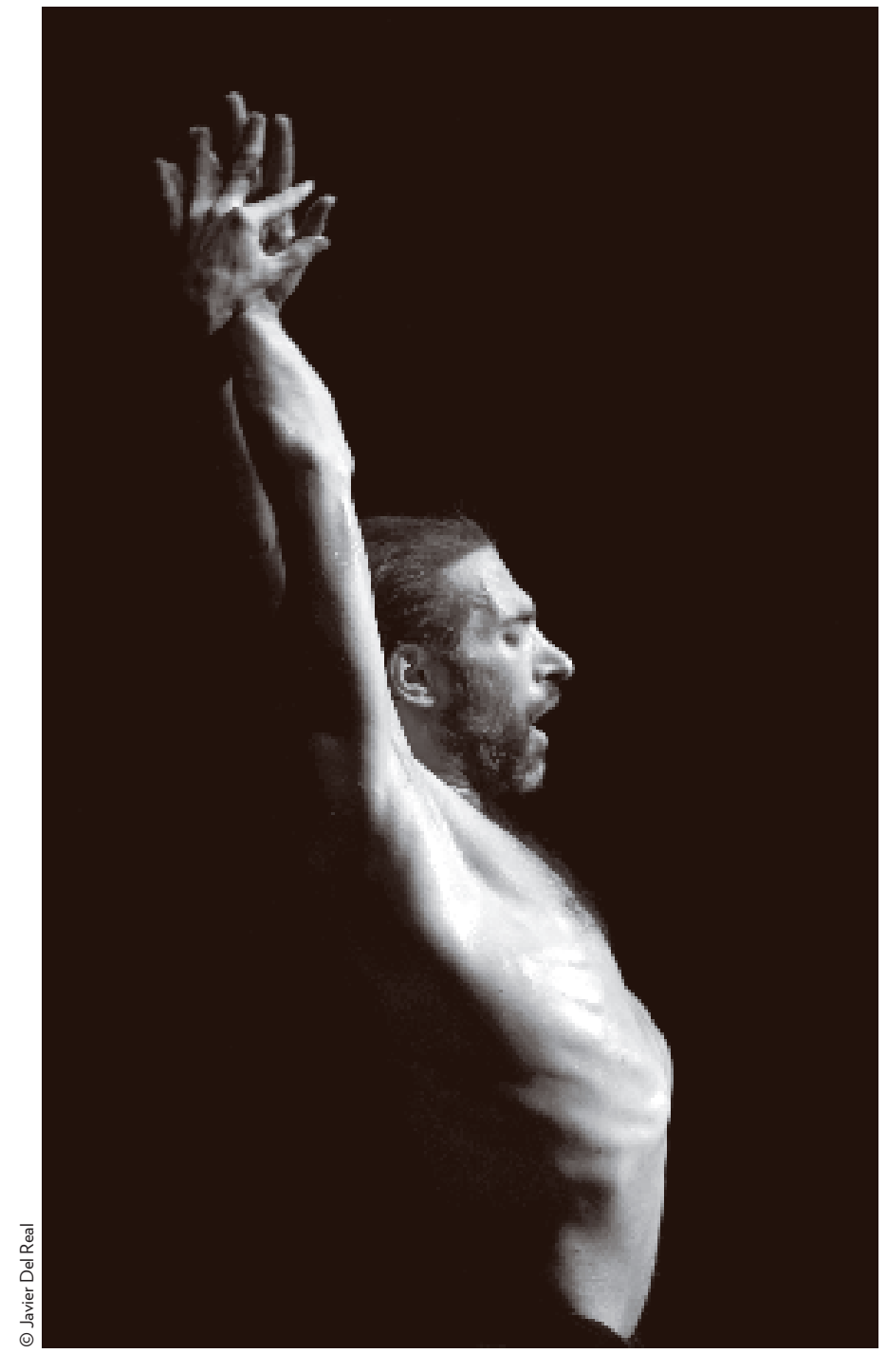

réel sont battus, flagellés et l'énergie du mouvement fonde le geste. Le réel ici n'est pas la quête d'un sens, dans le silence de cette première scène I'austérité ce temps premier cède le pà un en. Lauséré parate et cest dons l'assem a un ensente le sens se donne. Glavan ne suit aucun récit et préfère

(1) Terme espagnol de tauromachie qui caractérise le ralentissement
du rythme que le torero impose à a charge du tarear

tisser musique, chorégraphie et image dans un montage singulier Les voix naturelles et Lainas, ces envolées flamencas qui gravissent la danse en resserrant peu à pen le cercle autour du bailaor. Guitares et palmas partagent, avec les piano erigine " ditler in mes herte d'Anterpetation Jonhale de " Chiculo oui, selon l'intensité chorégraphique "Chicnt lis qui, selon lintencen jeuvz jusqù̀ des accorto dissonajondo l'im, Jusquâ des aco à partion partieduspostifschinge:despan projaction d' dex it du film Te Ton Gatlif, Ca projection dun extrait du film de Tony Gatil, Canta référe, a tieftand de Leni Riefe de wagon et la pour e propos du film que pour pour le propos dsinn que porr són mination par l'im mination par limage. Alors quelle n'est incorporée à denx ple que de facon pérphérique. Notons enfin deux passages dune grande vituosite: Isrique Gavan réssar ar les to Isan Riefensthal dans un reto lo den hefenthal dans un retoring allemand. Galvan nelâchejamais sonspectateur, dan thetenu ultime où redressant des paneles, jusquan la scin la scène, la refermant sur le camp, après avoir pointé du doiglasulle

Isabelle Galichon

Plus d'infos

$\diamond$ Lo real/Le réel/The real Une production du Teatro Real de Madrid en coproduction avec le Thêâtre de la Ville de Paris Danseurs: Israel Galvan, Belen Maya et Isabel Bayo Guitare: Juan Gomez "Chicuelo"

Danse, chant et jaleos: Caracafé, Bobote et Uchi

$\widehat{A}$ Torobaka, la dernière pièce d'Israel Galván en d'Akram Concertgebouw Bruges), au Royaume-Unile 3 novemb 2014 (Sadler's Wells, Londres) et aux Pays-Bas le 2 février 2015 (Stadsschouwburg Amsterdam). Le spectacle se jouera encor

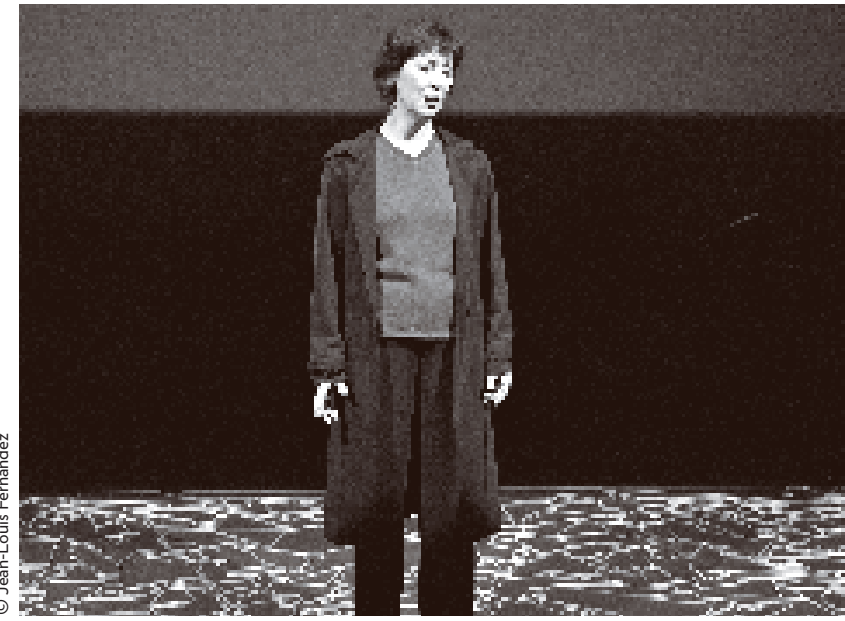

\section{MÉMORANDUM THÉÂTRAL}

$\longrightarrow$

13 mars au 17 mai 2014, le Théâtre (P) Femme non-rééducable. Mémorandum e par Anne Alvaro dans le rôle titre. La mémoire par Anne Alvaro dans le rốe titre. La affleure ̀n tiqueda remémoration, portée parlaprofération de la laremémoration, portée par laprofération maliste, se réduità l'incarno pardeux voixet un violon: costle mémoire d’Ann Politkovskä̈a en tant que parole testimoniale qui est mise en scène. Le décor fontomatique s'appuie sur un dispositif scénographique porté essentiellement par des effets de lumière et la perspective d'un bâtiment en ruine.

Cet exercice mémoriel proposé dans le cadre du théatre donne à voir une approche autre de la de retenir l'attention. Notons cependant ici que texte n'est pas celui du témoin.

Isabelle Galichon 